\title{
SYMPTOMATIC CORTICAL IRREGULARITIES OF THE DISTAL FEMUR SIMULATING MALIGNANCY
}

\author{
M. A. C. CRAIGEN, G. C. BENNET, J. R. MACKENZIE, R. REID \\ From the Royal Hospital for Sick Children and Western Infirmary, Glasgow, Scotland
}

We reviewed the records and radiographs of seven children who presented with knee pain, local tenderness over the medial femoral condyle, and radiological irregularity of the distal medial metaphysis of the femur suggestive of malignancy. In the five patients who had biopsies, histological changes were consistent with musculotendinous avulsion, and the dissection of ten cadavers confirmed the site to be the insertion of part of the adductor magnus. The recognition of this lesion and knowledge of its benign nature may avoid unnecessary anxiety and needless biopsy.

J Bone Joint Surg [Br] 1994; 76-B:814-7.

Received 20 July 1993; Accepted 27 October 1993

In children, the distal femur is a common site for benign and malignant tumours. Benign lesions are usually painless and radiologically well-defined. Malignant tumours usually present with local pain and tenderness and often show an increase in skin temperature. Radiographs may show destruction or expansion of the cortex, softtissue swelling and periosteal reaction.

Problems may occur with erosive lesions on the medial and posteromedial aspects of the femur which are asymptomatic and appear radiologically as benign features (Simon 1968; Barnes and Gwinn 1974; Velchik et al 1984).

We report seven children who presented with pain and localised tenderness over the medial femoral condyle in whom radiographs showed a cortical erosion on the medial border of the distal femoral metaphysis, with some features of malignancy.

\section{PATIENTS AND METHODS}

The seven children had a mean age of 11 years (Table I). Five were male and two female. One (case 3) presented directly to the Royal Hospital for Sick Children and two

Table I. Details of seven patients with cortical irregularities of the distal femur

\begin{tabular}{lccllll}
\hline \multicolumn{1}{c}{ Case } & Sex & $\begin{array}{c}\text { Age } \\
\text { (yr) }\end{array}$ & Symptoms & $\begin{array}{l}\text { Duration of } \\
\text { symptoms } \\
\text { (mth) }\end{array}$ & Radiology report & $\begin{array}{l}\text { Follow-up } \\
\text { (yr) }\end{array}$ \\
\hline 1 & M & 8 & Knee swelling & 2 & ? Malignancy & 2 \\
2 & F & 9 & Bilateral knee pain & 4 & ? Benign tumour & 6 \\
3 & M & 10 & $\begin{array}{l}\text { Knee pain radiating } \\
\text { to groin }\end{array}$ & 2 & $\begin{array}{l}\text { ? Malignancy } \\
\text { Bony spicules } \\
\text { in soft tissue }\end{array}$ & 1.5 \\
4 & F & 10 & Medial knee pain & 1 & Osteosarcoma & 2 \\
5 & M & 14 & Anteromedial knee pain & 18 & ? Malignancy & 2 \\
6 & M & 14 & Bilateral knee pain & 12 & ? Malignancy & 4 \\
7 & M & 15 & Posteromedial knee pain & 9 & ? Malignancy & 0.5 \\
\hline
\end{tabular}

M. A. C. Craigen, FRCS, Orthopaedic Registrar

G. C. Bennet, FRCS, Consultant Orthopaedic Surgeon

J. R. MacKenzie, FRCR, Consultant Radiologist

Royal Hospital for Sick Children, Yorkhill, Glasgow G3 8SJ, UK.

R. Reid, MRCPath, Consultant Pathologist

Scottish Bone Tumour Registry, Western Infirmary, Dumbarton Road, Glasgow G11 6NT, UK.

Correspondence should be sent to Mr M. A. C. Craigen at Room CF86, Centre Block, Southampton General Hospital, Tremona Road, Southampton SO9 4XY, UK.

(C)1994 British Editorial Society of Bone and Joint Surgery 0301-620X/94/5777\$2.00 had been referred from other hospitals. The other four cases were collected from the files of the Scottish Bone Tumour Registry.

Six of the children had local tenderness at the medial femoral condyle and one had a palpable swelling. All had a full range of movement at the knee, no effusion and no ligamentous instability. Blood tests including $\mathrm{Hb}$ level, WBC, ESR and serum biochemistry were normal in all cases.

Radiographs showed irregular, destructive cortical 


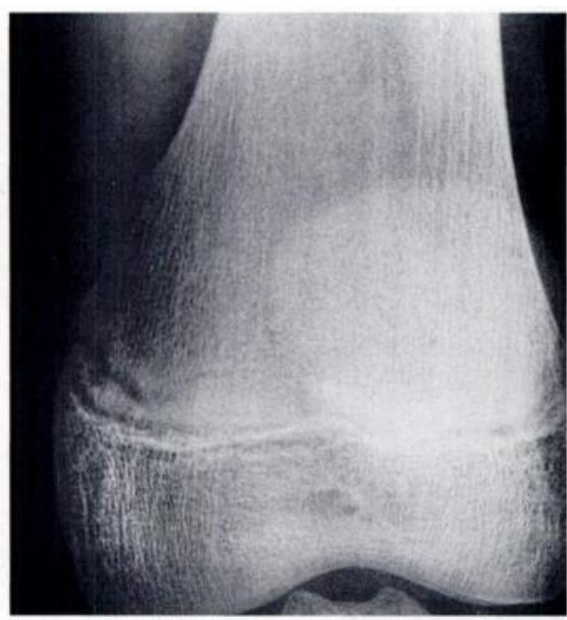

Fig. 1

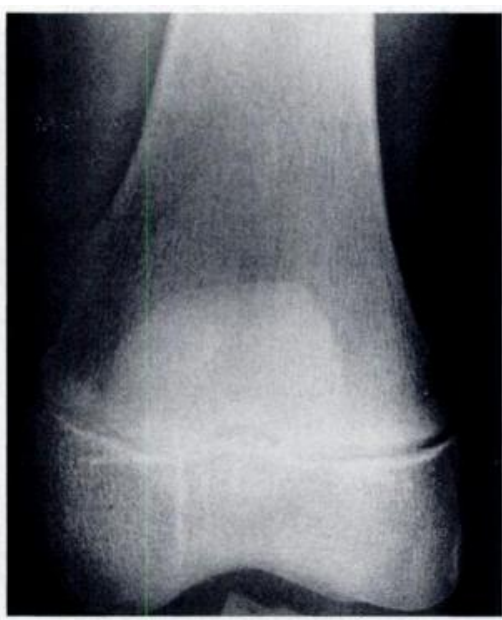

Fig. 2

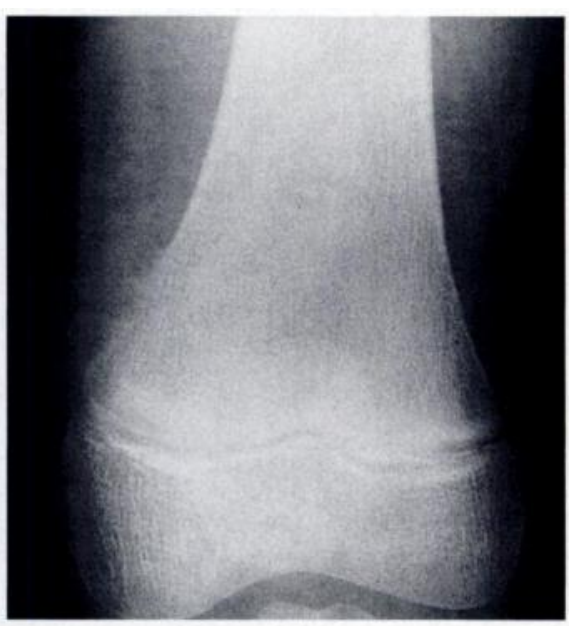

Fig. 3

Case 7. Figure 1 - Radiograph of a distal left femur, showing an erosive cortical lesion in the medial metaphysis. Case 6. Figure 2 - Radiograph showing a lesion with a periosteal reaction. Case 3 . Figure 3 - Radiograph showing bony spicules extending into the soft tissues.

lesions on the medial side of the distal metaphysis of the femur (Fig. 1). There was periosteal reaction in two, but neither of these showed any soft-tissue swelling (Fig. 2). In one case there were bone spicules extending into the soft tissues (Fig. 3). Four children had bone scans, all of which showed symmetrical uptake (Fig. 4).

Biopsy was performed in five patients, with similar histological findings. Most of the lesion consisted of fibroblastic tissue containing trabeculae of woven bone, some formed by rows of osteoblasts and others by metaplasia from the fibroblastic stroma. There was also some resorption of cortical and cancellous bone by osteoclasts. Nuclear pleomorphism was not marked, with only an occasional mitotic figure of normal morphology. The overall appearance was that of reparative proliferation of fibrous tissue with new bone formation (Fig. 5), considered to be consistent with musculotendinous avulsion. The other two children did not have biopsies; normal bone scans were considered to make this unnecessary.

The mean follow-up was 2.6 years. In three of the five children who had had biopsies their symptoms were relieved by the procedure. There was no radiological recurrence after biopsy, and in one patient who did not have a biopsy the lesion became surrounded by normal bone (Fig. 6).

Anatomy. We dissected the medial side of the distal end of the femur in ten adult cadavers. The area corresponding to the radiological lesions was found to be the site of insertion of that part of adductor magnus which is separated from the adductor tubercle by the superior geniculate vessels. This separate insertion was present in all ten specimens, but varied from a recognisable sheet of muscle or tendon (Fig. 7) to a thickening of the aponeurosis attached to the medial supracondylar ridge. Radiography after marking the soft tissues confirmed that the radiological lesions had all been at this adductor insertion (Fig. 8).

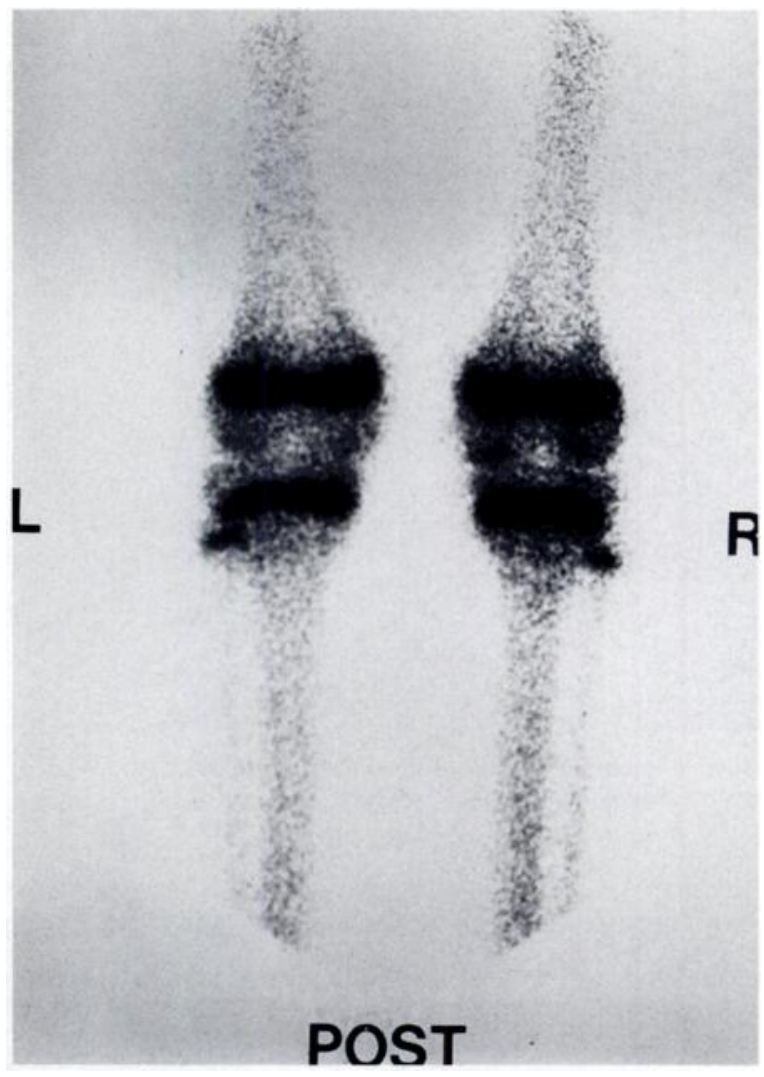

Fig. 4

Case 5. Bone scan of both distal femora showing equal and normal uptake on both sides.

Radiology. One of the authors (JRM) reviewed 100 consecutive anteroposterior and lateral radiographs of children's knees taken for any reason at the Royal Hospital for Sick Children. Five sets of radiographs showed irregularities on the medial aspect of the distal femur, but all were related to the metaphysis bordering the proximal 


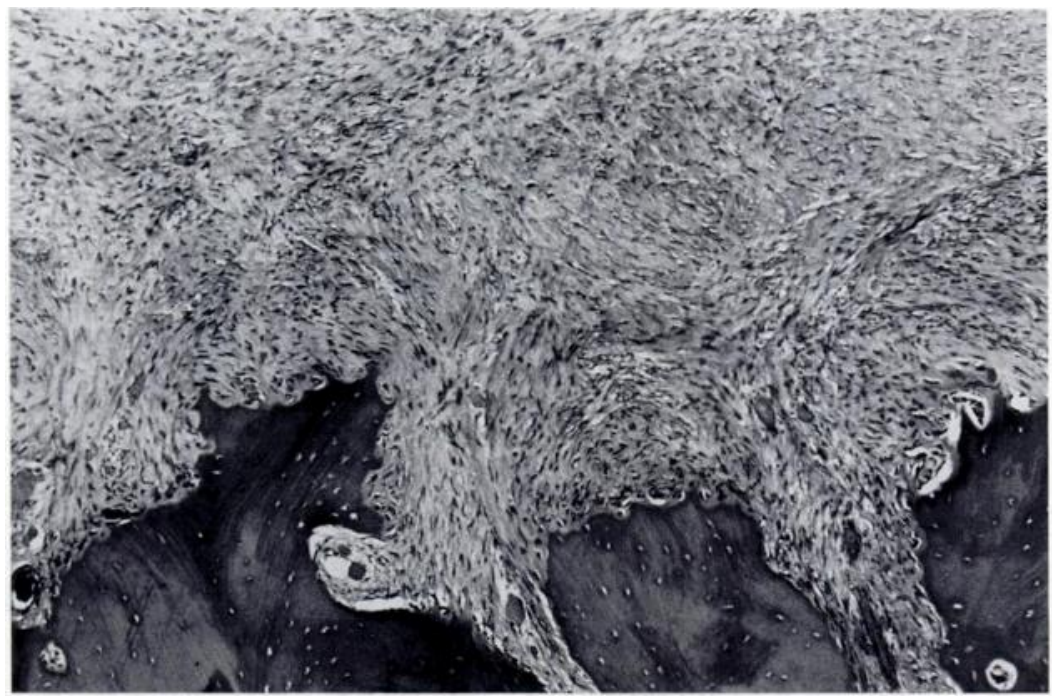

Fig. 5

Biopsy of a lesion showing cellular fibroblastic tissue. The border with bone is uneven due to osteoclastic activity. The appearance is consistent with musculotendinous avulsion (haematoxylin and eosin $\times 100$ ).

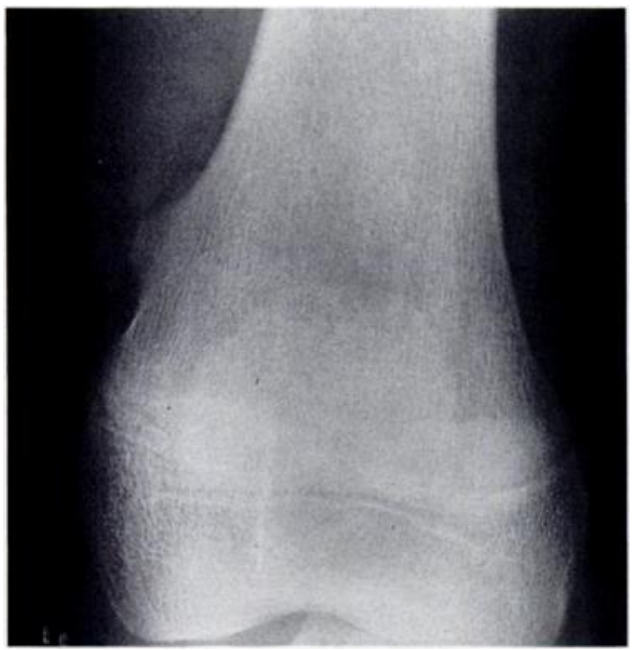

Radiograph showing healing of the lesion in Figure 1 with normal surrounding bone. edge of the epiphysis and none was in the area of the lesions described above (Fig. 9).

\section{DISCUSSION}

Benign bone irregularity on radiographs of the distal femur in children has been reported to occur in $11.5 \%$ of males and $3.6 \%$ of females (Simon 1968), varying from slight loss of cortical definition or roughening, to a ragged spiculation suggestive of early malignancy. Most of these lesions were incidental findings in asymptomatic patients.

Local pain and tenderness around the knee in this age group associated with cortical irregularity, periosteal reaction and spiculation in soft tissues must always raise the possibility of early malignancy, because osteosarcoma is most commonly found in the distal femur in adolescents.

Six of our patients had local pain and tenderness, and three had suspicious radiographic features, with ill-

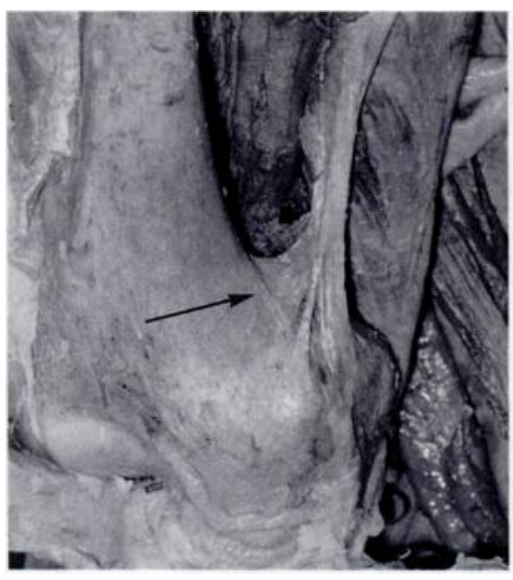

Fig. 7

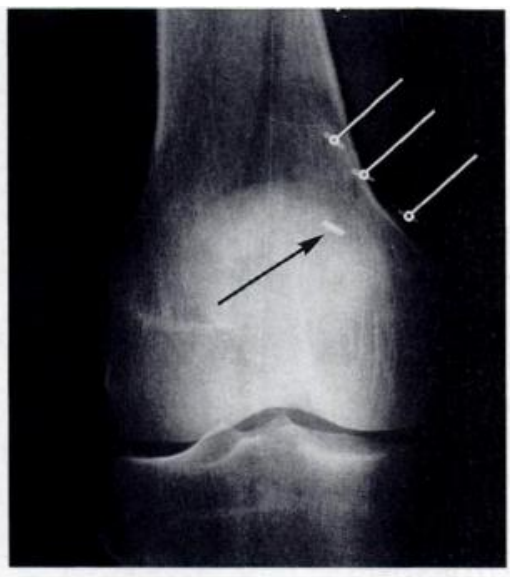

Fig. 8
Figure 7 - Dissected specimen of the distal right thigh showing the multiple tendinous insertions of adductor magnus (arrow) to the medial supracondylar ridge. Figure $8-$ Anteroposterior radiograph of a similar specimen, with markers at the three separate insertions of adductor magnus (circles) and the medial head of gastrocnemius (arrow). 


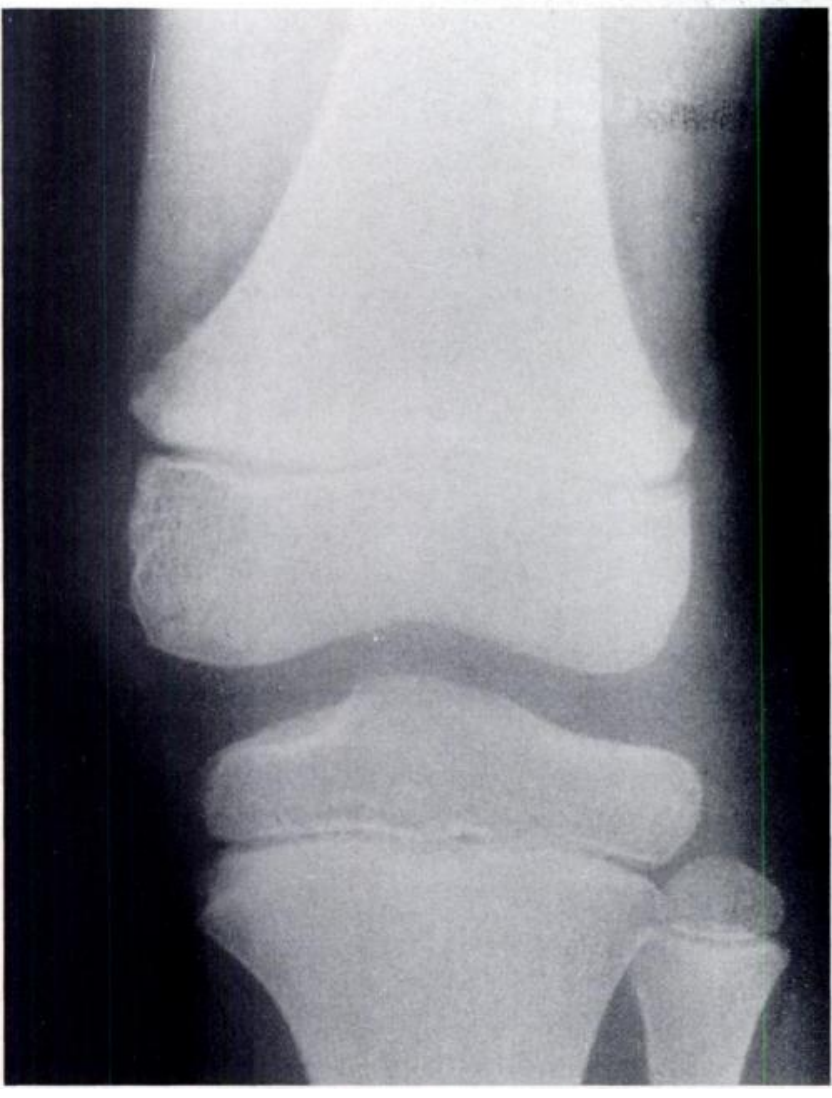

Fig. 9

Radiograph from the radiological review of 100 knees, showing the irregularity at the medial edge of the metaphysis which was found in five patients.

defined margins and periosteal reaction in two and calcification in the soft tissues in one.

Despite the fact that asymptomatic medial erosions are well described as normal radiological variations in textbooks (Keats 1988), the original radiological and orthopaedic diagnosis was malignancy in six of our cases.

There is some confusion about the aetiology and anatomical site of such lesions, and we agree with Resnick and Greenway (1982) that there are probably two types. The commonest is cortical excavation, visible on lateral

\section{REFERENCES}

Barnes GR, Gwinn JL. Distal irregularities of the femur simulating malignancy. Am J Roentgenol 1974; 122:180-5.

Brower AC, Culver JE, Keats TE. Histological nature of the cortical irregularity of the medial posterior distal femoral metaphysis in children. Radiology 1971; 99:389-92.

Dunham WK, Marcus NW, Enneking WF, Haun C. Developmental defects of the distal femoral metaphysis. J Bone Joint Surg [Am] 1980; 62-A:801-6.

Fulton MN, Albright JP, El-Khoury GY. Cortical desmoid-like lesion of the proximal humerus and its occurrence in gymnasts (Ringman's shoulder lesion). Am J Sports Med 1979; 7:57-61.

Johnson LC, Genner BA III, Engh CA, Brown RH. Cortical desmoids. J Bone Joint Surg [Am] 1968; 50-A:828. or oblique radiographs, and situated at the origin of the medial head of gastrocnemius. Cortical irregularities are not uncommon in this area, but this was not the site in our symptomatic patients. The difference may explain the confusion in the literature (Simon 1968; Barnes and Gwinn 1974).

We believe that the lesions in our patients were similar to the proliferative cortical irregularity described by Resnick and Greenway (1982), and that they were related to the insertion of adductor magnus (Barnes and Gwinn 1974).

The variation in the nomenclature of benign lesions in this area seems to be due to differences in histological interpretation. Brower, Culver and Keats (1971) suggested that some represented the early stages of fibrous cortical defect, and Johnson et al (1968) used the term 'cortical desmoid' which has neoplastic connotations. Dunham et al (1980) reported one case in which the appearances were interpreted as due to osteogenic sarcoma; an amputation was performed.

We believe that in our patients the lesions were due to reaction after partial avulsion of the insertion of adductor magnus: their location was correct and their histological appearance was similar to that reported after avulsion of the insertion of pectoralis major (Fulton, Albright and El-Khoury 1979). It seems possible that repeated microavulsions may be produced in children by muscles which are relatively stronger than their bony insertions. This could explain the absence of such lesions in adults.

Accurate diagnosis may be difficult. Others have reported that bone scans are usually normal in benign lesions of this type (Dunham et al 1980; Velchik et al 1984); we confirmed this in four of our cases. MRI has also been shown to differentiate normal variations at the distal end of the femur and may be the investigation of choice, when simpler tests are inconclusive (Sklar, Phillips and Lachman 1991).

No benefits in any form have been received or will be received from a commercial party related directly or indirectly to the subject of this article.

Keats TE. Atlas of normal roentgen variants that may stimulate disease. Fourth ed. Chicago, etc: Year Book Medical Publishers, 1988.

Resnick D, Greenway G. Distal femoral cortical defects, irregularities and excavations. Radiology 1982; 143:345-54.

Sklar DH, Phillips JJ, Lachman RS. Case report 683. Skeletal Radiol $1991 ; 20: 394-6$.

Simon H. Medial distal metaphyseal femoral irregularity in children Radiology 1968; 90:258-60.

Velchik MG, Heyman S, Makler PT, Goldstein HA, Alavi A. Bone scintigraphy: differentiating benign cortical irregularity of the distal femur from malignancy. $J$ Nucl Med 1984; 25:72-4. 